\title{
Biomedical Activity of Chitin/Chitosan Based Materials- Influence of Physicochemical Properties Apart from Molecular Weight and Degree of $N$-Acetylation
}

\section{Jolanta Kumirska $^{1, *}$, Mirko X. Weinhold ${ }^{2}$, Jorg Thöming ${ }^{2}$ and Piotr Stepnowski ${ }^{1}$}

1 Faculty of Chemistry, University of Gdansk, Sobieskiego 18/19, PL-80-952 Gdansk, Poland; E-Mail: sox@chem.univ.gda.pl (P.S.)

2 UFT - Centre for Environmental Research and Sustainable Technology, University of Bremen, Leobener Straße UFT, D-28359 Bremen, Germany; E-Mails: mirkoweinhold@gmx.de (M.X.W.); thoeming@uni-bremen.de (J.T.)

* Author to whom correspondence should be addressed; E-Mail: kumirska@chem.univ.gda.pl; Tel.: +48-58-523-5470; Fax: +48-58-523-5454.

Received: 31 August 2011; in revised form: 14 October 2011 / Accepted: 2 November 2011 / Published: 3 November 2011

\begin{abstract}
The physicochemical nature of chitin and chitosan, which influences the biomedical activity of these compounds, is strongly related to the source of chitin and the conditions of the chitin/chitosan production process. Apart from widely described key factors such as weight-averaged molecular weight $\left(\mathrm{M}_{\mathrm{W}}\right)$ and degree of $N$-acetylation (DA), other physicochemical parameters like polydispersity $\left(\mathrm{M}_{\mathrm{W}} / \mathrm{M}_{\mathrm{N}}\right)$, crystallinity or the pattern of acetylation $\left(P_{\mathrm{A}}\right)$ have to be taken into consideration. From the biological point of view, these parameters affect a very important factor - the solubility of chitin and chitosan in water and organic solvents. The physicochemical properties of chitosan solutions can be controlled by manipulating solution conditions (temperature, $\mathrm{pH}$, ionic strength, concentration, solvent). The degree of substitution of the hydroxyl and the amino groups or the degree of quaternization of the amino groups also influence the mechanical and biological properties of chitosan samples. Finally, a considerable research effort has been directed towards developing safe and efficient chitin/chitosan-based products because many factors, like the size of nanoparticles, can determine the biomedical characteristics of medicinal products. The influence of these factors on the biomedical activity of chitin/chitosan-based products is presented in this report in more detail.
\end{abstract}


Keywords: chitin; chitosan; biomedical activity; structure-property-activity relationships; ionic strength; $\mathrm{pH}$; chitosan source; degree of substitution; degree of quaternization

\section{Introduction}

Chitin and chitosan (Figure 1) are linear polysaccharides consisting of varying amounts of $\beta$-( $1 \rightarrow 4)$-linked 2-amino-2-deoxy- $\beta$-D-glucopyranose $(\mathrm{GlcN})$ and 2 -acetamido-2-deoxy- $\beta$-D-glucopyranose (GlcNAc) residues [1,2]. Chitin samples contain a high content of GlcNAc units, whereas chitosan mainly consists of GlcN units. Some authors believe that chitin is built up of at least $60 \%$ of GlcNAc residues [3], although a rigid nomenclature with respect to the degree of $N$-acetylation (defined as the average number of GlcNAc units per 100 monomers expressed as a percentage, DA) between chitin and chitosan has not been defined [4]. It should be mentioned that both compounds are insoluble in water $(\mathrm{pH}=7)$ and common organic solvents, although they can be dissolved in specific solvents such as hexafluoro-2-propanol, $N, N$-dimethylacetamide or hexafluoroacetone [5-7].

Figure 1. Schematic representation of chitin and chitosan derivatives. Through functionalization of the chemical structure, the solubility of the almost insoluble biopolymer chitin (a) can be enhanced. Quaternized (c) and substituted (d) derivatives also show much better solubility under alkaline conditions than chitosan (b).

increasing solubility

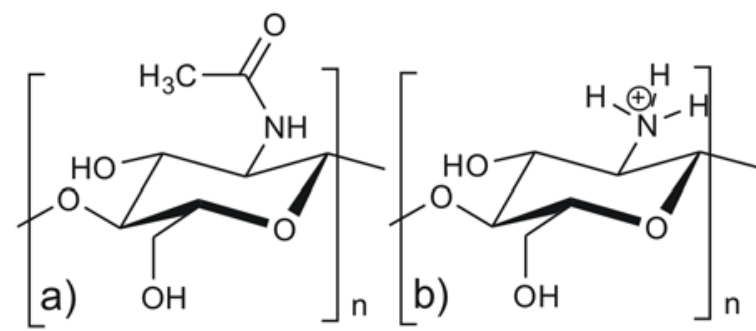

raw chitin (insoluble) chitosan (acidsoluble)

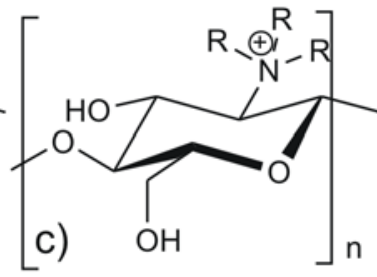

quaternized chitosan (soluble)

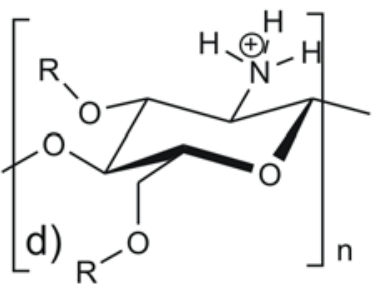

substituted chitosan (soluble)

Chitin is, next to cellulose, the second most abundant natural biopolymer. It is found predominantly in the shells of crustaceans such as crabs and shrimp, the cuticles of insects, and the cell walls of fungi [8]. Its biosynthesis by living organisms in the lower plant and animal kingdoms has been estimated at $10^{10}-10^{12}$ tons/year [9]. On the other hand, chitosan is produced only by some fungi Mucoraceae [10]. Commercial chitosan samples are typically prepared by the chemical de- $N$-acetylation of chitin under alkaline conditions [11-14]. Depending on the source of natural chitin $[1,15,16]$ and the conditions of its production, chitosan preparations can differ in size (average molecular weight; $\left.\mathrm{M}_{\mathrm{W}}\right)$, DA and other physicochemical properties such as polydispersity $\left(\mathrm{M}_{\mathrm{W}} / \mathrm{M}_{\mathrm{N}}\right)$, crystallinity or the pattern of acetylation $\left(P_{\mathrm{A}}\right)$ [16-20]. 
Chitin and chitosan possess very interesting biological properties (Figure 2); therefore, they have been used in many applications, mainly in the medical and pharmaceutical fields [4,17,19,21-30]. Not all biological activities have been observed with every chitin/chitosan preparation [31].

Figure 2. Biological properties of chitin and chitosan.

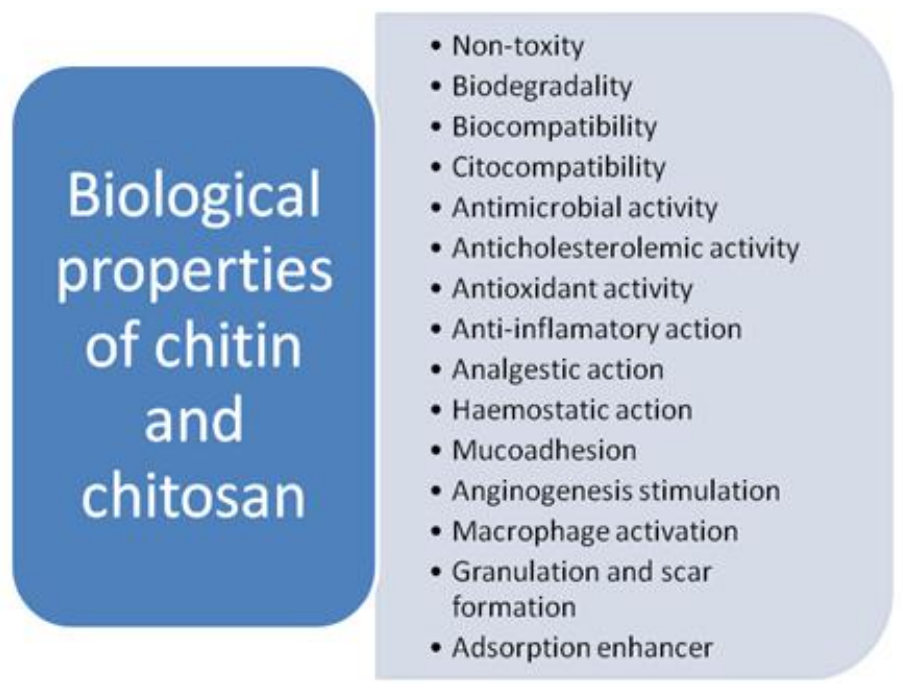

The biological properties of these compounds depend strongly on their solubility in water and other commonly used solvents. In its crystalline form, chitosan is normally insoluble in aqueous solutions above $\mathrm{pH}$ 7; however, in dilute acids, the protonated free amino groups facilitate the solubility of the molecule. The pKa of primary amino groups depends closely on DA, so the solubility of chitosan is also dependent on DA [6]. Being a highly insoluble and chemically rather unreactive material, chitin has a much lower applicability than chitosan. Recently, there has been growing interest in the chemical modification of chitosan and chitin (e.g., [32-35]) in order to improve their solubility and extend their applications (e.g., [7,19,36,37]).

Knowledge of the microstructure of chitosan samples is essential for understanding the structure-property-activity relationships of chitin and chitosan products [18,38-42]. To date, only the effect of weight-averaged molecular weight $\left(\mathrm{M}_{\mathrm{W}}\right)$ and degree of $N$-acetylation (DA) on the physicochemical and biological properties of these compounds has been intensively investigated. The results are summarized in a number of papers, (e.g., [17,21,43-46]). Selected relationships between the structural parameters DA and $\mathrm{M}_{\mathrm{W}}$, and the physicochemical and biological properties are presented in Figure 3.

As already mentioned, the biological properties of chitin/chitosan samples can also be related to the polydispersity $\left(\mathrm{M}_{\mathrm{W}} / \mathrm{M}_{\mathrm{N}}\right)$, crystallinity and distribution of GlcNAc and GlcN units along the polymeric chain described by the pattern of acetylation $\left(P_{\mathrm{A}}\right)$ [17,18]. When a chitosan solution is used in the investigations, factors such as concentration, the nature of salt counterion, $\mathrm{pH}$, ionic strength, and the addition of non-aqueous solvent should be taken into account [47]. Apart from these factors, the use in medical chitin/chitosan-based products of finely divided powders, films, membranes, gels, coatings, suspensions and hydrogels (e.g., [30,37,48-50]) can influence their biomedical activity [6,51-54]. 
Figure 3. Influence of degree of $N$-acetylation (DA) and molecular weight $\left(\mathrm{M}_{\mathrm{W}}\right)$ on the physicochemical and biological properties of chitin/chitosan samples.

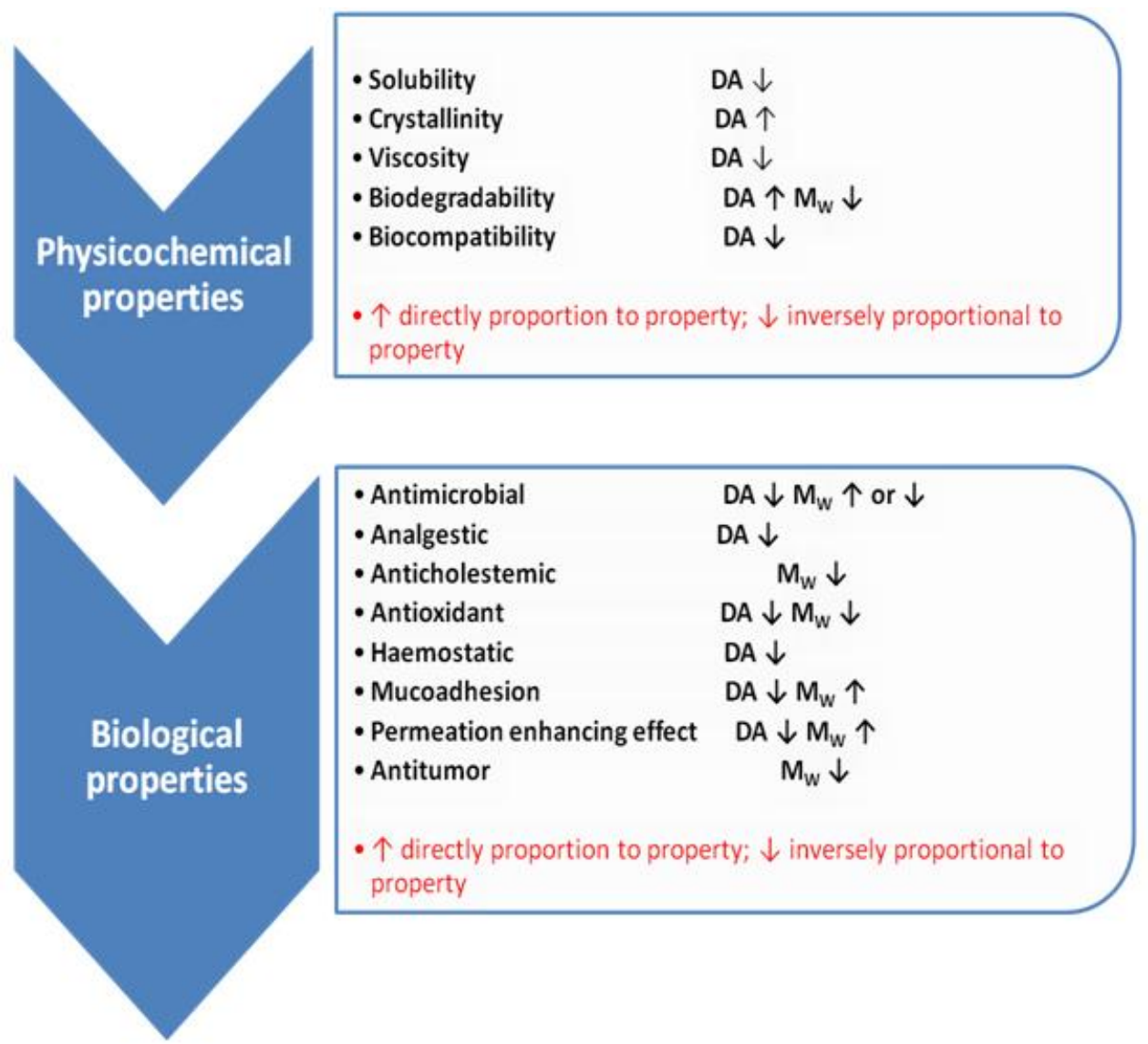

The aim of this review paper is to highlight the relationship between other key factors apart from the DA and $\mathrm{M}_{\mathrm{W}}$ properties of the chitin/chitosan-based materials and their biomedical activity. Special emphasis will be placed on the influence of such parameters as the source of chitin and chitosan, $\mathrm{pH}$, ionic strength, concentration, degree of quaternization, degree of substitution, and the preparation techniques of chitin/chitosan-based products offered for biomedical and pharmaceutical applications.

\section{Influence of the Sources of Chitin and Chitosan}

Although chitin is biosynthesized by more than $10^{6}$ species in three polymorphic configurations $(\alpha$, $\beta$, and $\gamma$-see Figure 4), in laboratories or on an industrial scale it is usually isolated from the exoskeletons of crustaceans, particularly shrimps and crabs [16]. $\alpha$-Chitin is obtained in this way [55]. $\beta$-Chitin can be extracted from squid pens, and $\gamma$-chitin from fungi and yeast [56]. $\alpha$-Chitin is the most common form, whereas $\beta$-chitin is more reactive [57] and shows a higher affinity for solvents [58]. $\beta$-Chitin is easily converted to $\alpha$-chitin by alkaline treatment followed by flushing in water [59]. 
Figure 4. Schematic representation of the three polymorphic forms of chitin (a) $\alpha$-chitin. (b) $\beta$-chitin. (c) $\gamma$-chitin.

a)

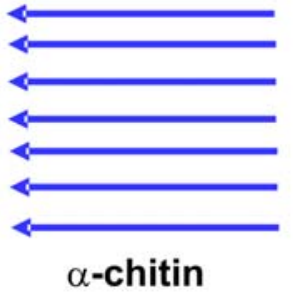

b)

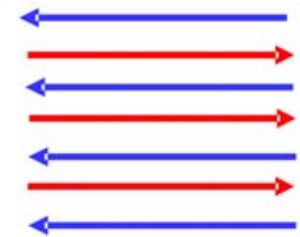

$\beta$-chitin c)

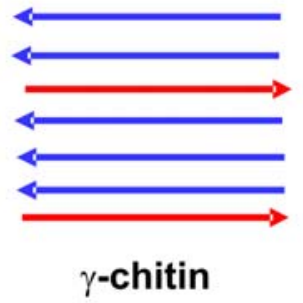

Youn et al. [60] demonstrated that selected physicochemical and functional properties of chitosans prepared from the shells of crabs harvested in three different years $(2004,2005$, and 2007) differed according to the crab harvest and/or storage duration of shells. Chitosan prepared from the chitin collected in 2004 showed a higher degree of deacetylation, was less viscous, and less red in color than that prepared from the chitin harvested in 2005 and two years later. The shells of the crabs from 2004 and 2005 contained similar amounts of protein, chitosan and ash, whereas the sample from 2007 had higher protein and chitin but a lower ash content. Furthermore, the chitosan prepared from chitin isolated in 2004 exhibited a greater water-binding capacity, dye-binding capacity and DPPH (2,2-diphenyl-1-picrylhydrazyl) radical scavenging activity than those from 2005 and 2007. This indicates that storage of crab shells for a certain period of time may be advantageous for chitosan production with improved functionality for particular uses.

It is well known that chitosan samples are usually prepared from $\alpha$-chitin isolated from crab shells by partial or complete de- $N$-acetylation of the chitin in the solid (a heterogeneous process) [16,20]. Recently, more attention has been paid to the production of chitin and chitosan from fungal sources [61,62]. Wu et al. [61], determined the yield (alkali-insoluble material, crude chitin, and the glucosamine content in crude materials) and physicochemical properties (DA, crystallinity) of chitin and chitosan isolated from Aspergillus niger and Mucor rouxii; they examined the bioactivity of fungal chitin and chitosan against the food-borne pathogen Salmonella Typhimurium and the plant pathogens Botrytis cinerea and Penicillium expansum. The biological properties of these samples were compared with those obtained for commercial chitosan obtained from crustacean shells. The authors established that the mycelium of $M$. rouxii contained a higher level of glucosamine than $A$. niger, and that both chitin and chitosan were present in $M$. rouxii mycelia, but only chitin in $A$. niger. The degree of $N$-acetylation of chitin from $A$. niger was higher than that of chitin and chitosan isolated from $M$. rouxii. The crystallinity of fungal chitin and chitosan was less intense than in the corresponding materials from shrimp shells. Despite these physicochemical differences, the antimicrobial activity of the isolated chitin and chitosan against Salmonella Typhimurium and plant pathogens B. cinerea and $P$. expansum was similar and comparable with that obtained from commercially purified crustacean chitosan. Differences in the conditions of chitin de- $N$-acetylation (e.g., temperature, alkali concentration, ratio of alkali solutions to the shells) may exert a strong influence on chitosan preparations [20]. Kamil et al. [63] described the effect of chitosans prepared using different de- $\mathrm{N}$-acetylation times (for 4, 10 and $20 \mathrm{~h}$ ) on lipid autoxidation in a fish model system. These chitosan preparations were similar in their degree of $\mathrm{N}$-acetylation, nitrogen content, ash, color, 
moisture, viscosity and molecular weight, but differed in their apparent viscosity. The viscosity was highest when de- $N$-acetylation was carried out for $4 \mathrm{~h}$ (360 centipoises units, $360 \mathrm{cP}$ ), less when this reaction lasted for over $10 \mathrm{~h}(57 \mathrm{cP})$ and least after $20 \mathrm{~h}(14 \mathrm{cP})$. The results showed that $14 \mathrm{cP}$ chitosan was more effective than the higher viscosity chitosans in preventing lipid oxidation in the herring flesh model system. In other research [64], the effect of de- $N$-acetylation time on the preparation, properties and swelling behavior of chitosan films was tested. Five types of chitosan films were prepared in a single-step de- $N$-acetylation process by varying the alkaline treatment time from 2 to $10 \mathrm{~h}$; the degree of $\mathrm{N}$-acetylation, crystallinity index (CrI), swelling index, contact angle and the morphology using scanning electron microscopy were determined. DA turned out to be similar for all chitosans. The film prepared during $2 \mathrm{~h}$ de- $N$-acetylation has a lower $\mathrm{CrI}$ and maximum swelling index, whereas the film formed after $6 \mathrm{~h}$ deacetylation had the lowest DA with higher CrI and low contact angles, and was more suitable for biomedical applications.

Problems with the production of a large spectrum of chitin/chitosan structures with perfect control of the chemical architectures, molecular weights and molecular weight distributions were described by Domard [20]. In this interesting review the author summarized his team's almost 30-year long research into chitin and chitosan, e.g., the production of chitin, chitosan and series of co-polymers and co-oligomers and their characterizations. The control of the physicochemical characteristics of chitin and chitosan is important in all biomedical applications, e.g., in tissue engineering. The regulation of porosity and pore morphology of chitosan-based scaffolds is critical for controlling cellular colonization rates and organization within an engineered tissue [65]. In addition, the angiogenesis required for some scaffold application scenarios can be affected by scaffold porosity and pore morphology [66].

\section{Influence of pH}

The presence of amino groups means that the $\mathrm{pH}$ substantially alters the charged state and the properties of chitosan (Figure 5).

Figure 5. Schematic illustration of chitosan's versatility.

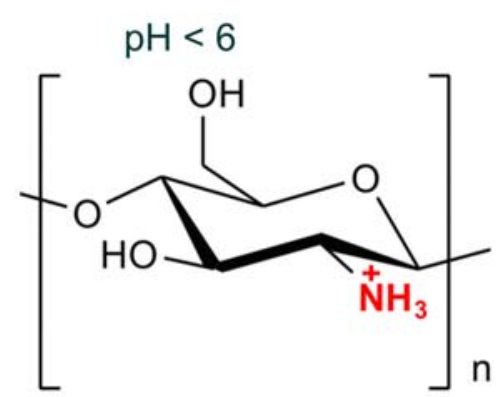

Soluble

Electrostatic interactions with negatively charged molecules such as anionic glycosaminoglycans proteoglycans phospholipids negatively charged liposomes

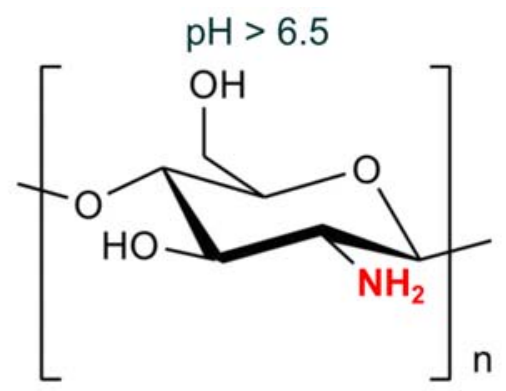

Insoluble

Hydrophobic interactions with e.g.

fatty lipids cholesterol non-charged liposomes 
At $\mathrm{pH}>6.5$ chitosan solutions exhibit phase separation, while at $\mathrm{pH}<6.5$ chitosan is soluble, carrying a positive charge because of the presence of protonated amino groups [67]. At $\mathrm{pH}$ between 6.0 and 6.5 in solution, the free amino groups of chitosan molecules become less protonated and hydrophobicity along the chitosan chain increases. Therefore, chitosan self-aggregates could be formed in acetate buffer solutions by intra- and inter-molecular hydrophobic interactions. As a cationic polyelectrolyte, at low $\mathrm{pH}$ (less than about 6) chitosan can electrostatically interact with negatively charged molecules or polymers, e.g., anionic glycosaminoglycans, proteoglycans, and other negatively charged molecules. At higher $\mathrm{pH}$ (above about 6.5) chitosan's amino groups are deprotonated and hydrophobic interactions with several substrates (e.g., fatty acids and cholesterol) can appear (Figure 5) [21].

These $\mathrm{pH}$-dependent properties of chitosan influence its biomedical activity and potential applications. One of them is the antimicrobial activity of chitosan [46]. The antibacterial mechanism of chitosan is generally considered to be due to its positively charged amino group at the C-2 position of the GlcN residue, which interacts with negatively charged microbial cell membranes, leading to the leakage of proteinaceous and other intracellular constituents of the microorganisms [68]. The presence of a large number of non-protonated amino groups as well as the poor solubility of chitosan at pH 7 [69-71] mean that chitosan's bactericidal activity is minimal. Helander et al. [72] reported that chitosan displayed antibacterial activity not only in an acid environment, although showed a stronger inhibitory effect at lower pHs with the inhibitory activity weakening with increasing pH. Kong et al. [73] and Yang et al. [74] observed that the antibacterial activity of the $N$-alkylated chitosan derivatives against $E$. coli increased as the $\mathrm{pH}$ rose from 5.0 reaching a maximum around $\mathrm{pH}$ 7.0-7.5. Also, the investigation of the antibacterial property of chitosan microspheres (CM) in a solid dispersing system showed that under neutral conditions, of the three tested CM samples with DA of 2.5, 16.5, 37.4\% respectively, the highest inhibitory effect was observed for the CM sample with DA of 37.4\% [73]. To date, there has been no positive information about the antimicrobial activity of chitosan under alkaline conditions.

The $\mathrm{pH}$ values of the medium also determines the stability of chitooligomers with the degree of polymerization $(\mathrm{DP})<20$, which can be achieved by depolymerization of chitosan [75]. These compounds have various biological activities such as antitumor and immune enhancing effects [76], but can easily turn brown during shelf life, which influences their properties and limits their applications in many fields. It was established that the $\mathrm{pH}$ of chitooligomers for their optimal preservation should be below 4 or above 10, and in an oxygen-free environment. It was also reported that syneresis (the major properties of hydrogels, which allows a more stable state to be achieved than the initial state of chitin gels) depends on $\mathrm{pH}$ [77].

Chitosan micro/nanoparticles based on ionic interaction between drugs (insulin, diclofenac sodium and salicylic acid respectively) and chitosan were prepared and examined for their influence on $\mathrm{pH}$ [78]. Entrapment efficiency and the amount of drugs inside the particles were affected by the zeta potential and surface charge of the micro/nanoparticles produced, whereas immediate drug release was independent of the $\mathrm{pH}$ of the dissolution medium.

In another investigation, chitosan was blended with different amounts of polycaprolactone (PCL) and used to control the delivery of ofloxacin [79]. The swelling kinetics as well as the drug delivery systems using ofloxacin have also been studied at different $\mathrm{pH}(\mathrm{pH} 3.4$ and 7.4) and drug loading. The 
percentage of swelling rises with $\mathrm{pH}$ increase from 3.4 to 7.4 , and with increase in the percentage of drug loading.

The influence of the $\mathrm{pH}$ of the release medium on the in vitro release of pDNA from chitosan microparticles was also investigated [80]. It was observed that the release of pDNA from chitosan microparticles in simulated gastric $(\mathrm{pH} 2.1)$, simulated intestinal $(\mathrm{pH}$ 6.47) and acidic PBS (pH 4.5) medium was $\mathrm{pH}$-dependent: as the $\mathrm{pH}$ of the release medium increased, the release profile decreased. The differences in the release profiles were explained by the different solubilities of chitosan in the acidic and basic $\mathrm{pH}$ of the media.

In another investigation [81], the influence was studied of $\mathrm{pH}$ on the entrapment efficiency of lipase from Candida rugosa in photo-cross-linkable chitosan membranes modified by $\alpha$-cyano-4hydroxycinnamic acid. The efficiency of the immobilization was evaluated by examining the relative enzymatic activity of the free enzyme before and after the immobilization of lipase. The optimal $\mathrm{pH}$ for immobilized lipase was found to be 8.0, which was slightly higher than that of the free lipase ( $\mathrm{pH} 7.5$ ), and the immobilization resulted in enzyme stabilization over a broader $\mathrm{pH}$ range.

Bernkop-Schnürch and Krajicek [82] synthesized different chitosan-EDTA (EDTA, ethylenediaminetetraacetic acid) conjugates to evaluate their potential regarding mucoadhesion, viscosity and inhibitory effects on the proteolytic activity of enzymes. Although the complexing agent lost one of its carboxylic acid groups (formation of an amide bond between the amino groups of the polymer), the modification did not much affect its ability to form complexes with bivalent cations. The binding capacity of chitosan-EDTA conjugates was not only tested under intestinal $\mathrm{pH}$-conditions but also at $\mathrm{pH}>9.0$. The results demonstrated that all chitosan-EDTA conjugates exhibited a greater capacity to bind zinc and cobalt than calcium. Whereas the capacity to bind calcium and cobalt could be enhanced in an alkaline medium, the $\mathrm{pH}$ had hardly any effect on the amount of zinc bound to polymers.

Schematic representation of influence of $\mathrm{pH}$ on the selected physicochemical and biological properties of chitin/chitosan samples is presented in Figure 6.

Figure 6. Influence of $\mathrm{pH}$ on the selected physicochemical and biological properties of chitin/chitosan samples.

\section{$\mathrm{pH} \uparrow$}

Syneresis up to $\mathrm{pH} 4$ [77]

Drug loading [79]

Entrapment efficiency [81]

Cobalt/calcium capacity [82]

Immune enhancing effect $\mathrm{pH}<4$

or $\mathrm{pH}>10$ [76]
Syneresis $\mathrm{pH}>4$ [77]

Antimicrobial properties [68-74]

Antitumor properties $4<\mathrm{pH}>10$

[76]

Immune enhancing effect $4<\mathrm{pH}$ $>10$ [76]

Permeation enhancing effect [80] 


\section{Influence of Ionic Strength}

Like $\mathrm{pH}$, ionic strength plays an important role in the physicochemical properties of chitosan solutions and can strongly influence their biological behavior (Figure 7). Nevertheless, up to now the significance of this factor on the biomedical activities of chitin/chitosan-based products has been characterized very poorly. Rinaudo et al. [83] described the influence of ionic strength on chitosan chain expansion. The role of ionic strength on the electrostatic effects due to the existence of charged $-\mathrm{NH}_{3}{ }^{+}$in acid conditions was tested by measurement of the intrinsic viscosity in solvents with different ionic concentrations.

Figure 7. Influence of ionic strength on the physicochemical properties of chitin/chitosanbased materials.

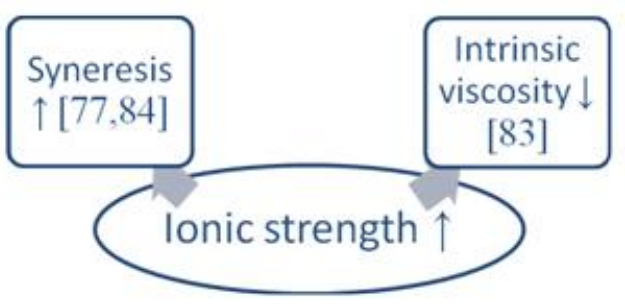

In another investigation [84], the effect of ionic strength on the stabilizing properties of chitosan in a model emulsion system containing whey protein isolate (WPI) as emulsifier and canola oil was studied. Syneresis was favored by the increasing ionic strength to $0.3 \mathrm{M}$.

Vachoud et al. [77] examined the role of the concentration of $\mathrm{KCl}$ initially present in the hydroalcoholic solution on gel formation, syneresis and the mechanical properties of the gel for two values of $R-2.5$ and 10 -where $R$ the molar ratio of $\mathrm{Ac}_{2} \mathrm{O}$-amine residues used for its preparation. It was established that the time necessary to achieve the gel point increased with $\mathrm{KCl}$ concentration independently of $R$. In the presence of salt, the rate of solvent exclusion during syneresis decreases when the concentration of salt increases for these two gels.

\section{Influence of Concentration}

The biomedical behavior of chitin/chitosan-based products also depends on the concentrations of these compounds.

The influence of concentration on the antimicrobial properties of these compounds is the most often described in literature (Figure 8). Ghaouth et al. [85] reported the effect of chitosan concentrations on the growth of Alternaria alternate, Botrytis cinerea, Colletotrichum gloeosporioides, and Rhizopus stolonifer. Abou Sereih Neven et al. [86] described the influence of five different doses of chitosan on the linear growth (mm) of Fusarium oxysporum f. sp. sesami and Trichoderma harzianum. The relationship between the concentrations of 12 kinds of new hydroxylbenzenesulfonailide derivatives of chitosan sulphates and carboxymethyl chitosan and antimicrobial activity against P. asparagi, A. solani, F. oxysporum f. sp. vasinfectum, C. gloeosporioides (Penz.) Saec and P. zingiber 
was presented by Zhong et al. [87]. The antibacterial activities of hydroxypropyl chitosan at different concentrations against Staphylococcus aureus and Escherichia coli have been explored by Xia et al. [88].

Apart from the influence of the chitosan concentration on its antimicrobial behavior, this parameter determines the properties of chitosan-based formulations for gene delivery systems $[51,89,90]$. It was established that the particle size of the chitosan/siRNA complex prepared by simple complexation increased when the concentration of chitosan was raised [51]. The comparative positive value of the surface charge (zeta potential) of chitosan-siRNA complexes also increased with the rising concentration of chitosan at a constant siRNA concentration. The transfection efficiency of the polyelectrolyte obtained depends on the mixing molar stoichiometry of DNA to chitosan (N/P ratio) $[51,89,90]$. Sajomsang et al. reported that the highest gene transfection efficiencies of all $\mathrm{N}$-aryl chitosan derivative/DNA complexes were observed at N/P ratios 5 due to the smallest particle size $(95-124 \mathrm{~nm})$ [89].

Figure 8. Schematic representation of chitosan's impact on the Gram-negative bacterium E. coli (a) and on brain cells (b). Bacteria show lysis accompanied by death in the presence of chitosan, whereas brain cells show a change in their overall shape; their functionality and vitality are, however, not affected by the chitosan treatment.

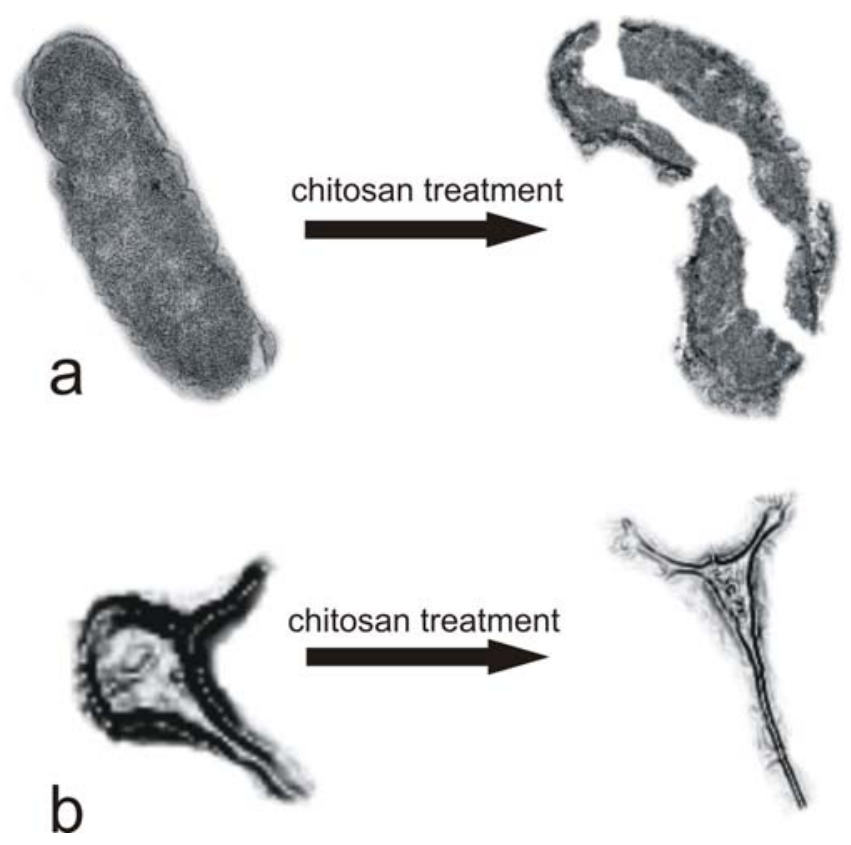

Zhu et al. [91] investigated the aggregation behavior of $O$-carboxymethylchitosan in dilute solution to demonstrate its potential use in drug delivery systems. The critical aggregation concentration was established between $0.042 \mathrm{mg} / \mathrm{mL}$ and $0.050 \mathrm{mg} / \mathrm{mL}$.

The influence of N/P ratio on the gene knockdown efficiency of chitosan $170 \mathrm{kDa}$ (DA 16\%) in H1299 human lung carcinoma cells was reported by Liu et al. [90]. They found that the level of EGFP knockdown increased at higher $\mathrm{N}: \mathrm{P}$ ratios (50 and 150) in comparison to lower $\mathrm{N}: \mathrm{P}$ ratios (2 and 10), and the nanoparticles formed at higher N:P (50 and 150) showed the greatest level (80\%) of EGFP knockdown. 
The hepatic cytotoxicity profile of chitosan nanoparticles in human liver progenitor cells with corresponding chitosan molecules as control was investigated by Loh et al. [92]. Both the chitosan molecules and nanoparticles induced CYP3A4 (the most abundant subfamilies of the cytochromes P450 in human liver ( $40 \%)$ which metabolizes more than $50 \%$ of clinically used drugs)-mediated activity in the BHAL cells, but the chitosan molecules exhibited a concentration-independent effect, while the nanoparticles showed a concentration-dependent effect within the concentration range from 0.01 to $1 \%$. The nanoparticles were less cytoadhesive than the chitosan molecules, although they were rapidly internalized by the BHAL cells. BHAL cells showed poor cell membrane integrity after exposure for $4 \mathrm{~h}$ to chitosan nanoparticles at concentrations $\geq 0.5 \% \mathrm{w} / \mathrm{v}$, which correlated to a higher leakage of alanine transaminase from the cells into the extracellular space.

The different weight ratios of chitosan to chondroitin $(\mathrm{CH} / \mathrm{CS})$ influence the pore structures, mechanical properties and surface hydrophilicity of sulphate chondroitin sulphate-modified chitosan membranes [93]. Membranes with the ratio CH/CS 90/10 were chosen as the most promising biomaterials for tissue engineering applications. Cai et al. [94] produced composite nanofibrous membranes of chitosan (CS) and silk fibroin (SF) by electrospinning. The antibacterial activity against E. coli (Gram-negative) and S. aureus (Gram-positive) increased greatly with increasing proportions of chitosan.

Yang et al. [95] reported that the tensile strength of the composite cellulose membranes coated with different chitosan concentrations increased with increasing chitosan concentration.

The chitosan concentration should also be controlled when chitosan is used as a surfactant [67]. The concentration above which a surfactant starts to form micelles or aggregates is called the critical micelle concentration (CMC) or the critical aggregate concentration (CAC), and the determination of this value for chitin/chitosan-based products is very important $[67,96]$. The initial concentration of chitin also has an important effect on the syneresis of chitin gels [77].

Schematic representation of influence of concentration on the selected physicochemical and biological properties of chitin/chitosan samples is shown in Figure 9.

Figure 9. Influence of concentration on the selected physicochemical properties and biological activity of chitin/chitosan based materials.

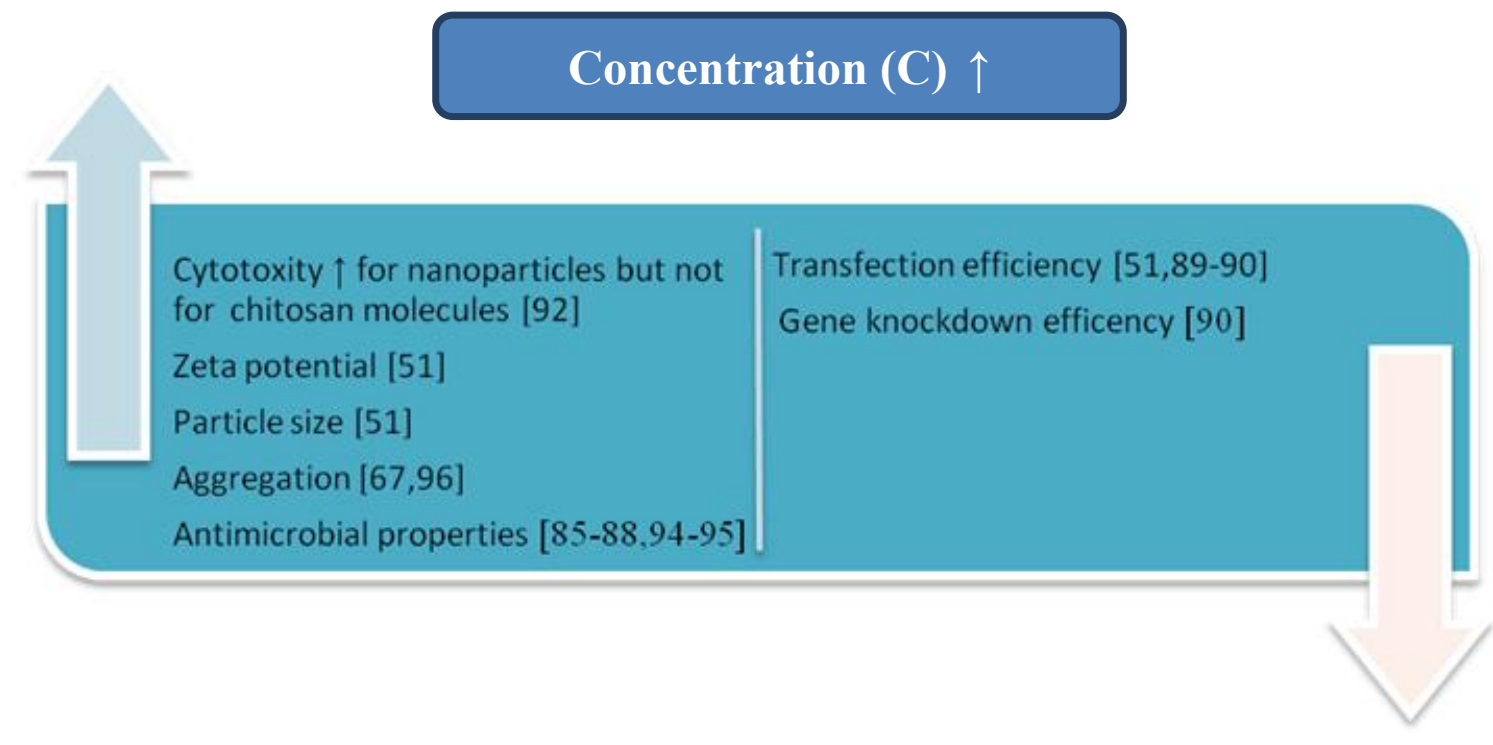




\section{Influence of the Degree of Quaternization}

$\mathrm{N}, \mathrm{N}, \mathrm{N}$-Trimethylammonium chitosan chloride (TMChC) was one of the quaternized chitosan derivatives firstly synthesized by Muzzarelli and Tanfani [97]. The influence of the degree of quaternization (DQ) on the mucoadhesive properties of TMChC was examined by Snyman, Hamman, and Kotze $[98,99]$. They demonstrated that the presence of quaternary ammonium groups decreased mucoadhesion and related this adverse effect to conformational changes in the TMChC. The opposite results were achieved by Sandri et al. (2005) [100]. Jintapattanakit et al. [101] established that TMChC with a relatively high degree of dimethylation (DD) exhibited higher mucoadhesion and cytotoxicity, and the mucoadhesive properties of these derivatives were influenced by the combination of molecular weight, the steric hindrance of the dimethyl groups on the polymer, and the positive charge density.

Sajomsang et al. [102] synthesized methylated $N$-aryl chitosan derivatives, methylated $N$-(4- $N, N$-dimethylaminocinnamyl) chitosan chloride (MDMCMCh) and methylated $N$-(4-pyridylmethyl) chitosan chloride (MPyMeCh) consisting of a variety of $N$-aryl substituents. The effects of the degree of quaternization (DQ) on mucoadhesion and cytotoxicity were investigated and compared to $N, N, N$-trimethylammonium chitosan chloride (TMChC). It was found that mucoadhesion and cytotoxicity increased when DQ was increased to $65 \%$, but decreased with DQ $>65 \%$. The influences of the quaternary and acyl groups on the in vitro anticoagulant activity of $N$-propanoyl-, $N$-hexanoyland $N, O$-quaternary substituted chitosan sulphate were also investigated [103]. It was established that the anticoagulant activity of the chitosan sulphate was enhanced by the $N$-acyl groups, whereas the quaternary groups decreased this activity. The influences of these groups may be attributed to the change in negative charge density and the arrangement of chitosan sulphate.

In another investigation [104] the antibacterial activity of a series of methylated chitosan and chitooligomer derivatives possessing various degrees of methylation against Staphylococcus aureus was examined. It was observed that $\mathrm{N}$-quaternization was mainly responsible for the antibacterial effects at $\mathrm{pH} 7.2$, whereas it did not contribute to the antibacterial activity under acidic conditions.

Sajomsang et al. [105] synthesized 17 derivatives of chitosan consisting of a variety of $N$-aryl substituents (ES parameter), and each of the derivatives was further quaternized using the quaternizing agent that reacted with either the primary amino or hydroxyl groups of the glucosamine residue of chitosan. All the quaternized derivatives of chitosan showed antibacterial activity, but derivatives with ES values higher than $20 \%$ exhibited low antibacterial activity. Probably a low quaternary ammonium moiety was obtained owing to the steric hindrance of the $N$-aryl substituents.

The influence of the DQ of $N, N, N$-trimethyl chitosan (TMC) on its adjuvanticity was also investigated [106]. The adjuvant properties of TMCs as an intranasal adjuvant are strongly decreased by the re- $N$-acetylation of TMC, whereas the DQ did not significantly affect this activity.

The most important results presented in this section are summarized in Figure 10. 
Figure 10. Influence of degree of quaternization on the selected physicochemical and biological properties of chitin/chitosan samples.

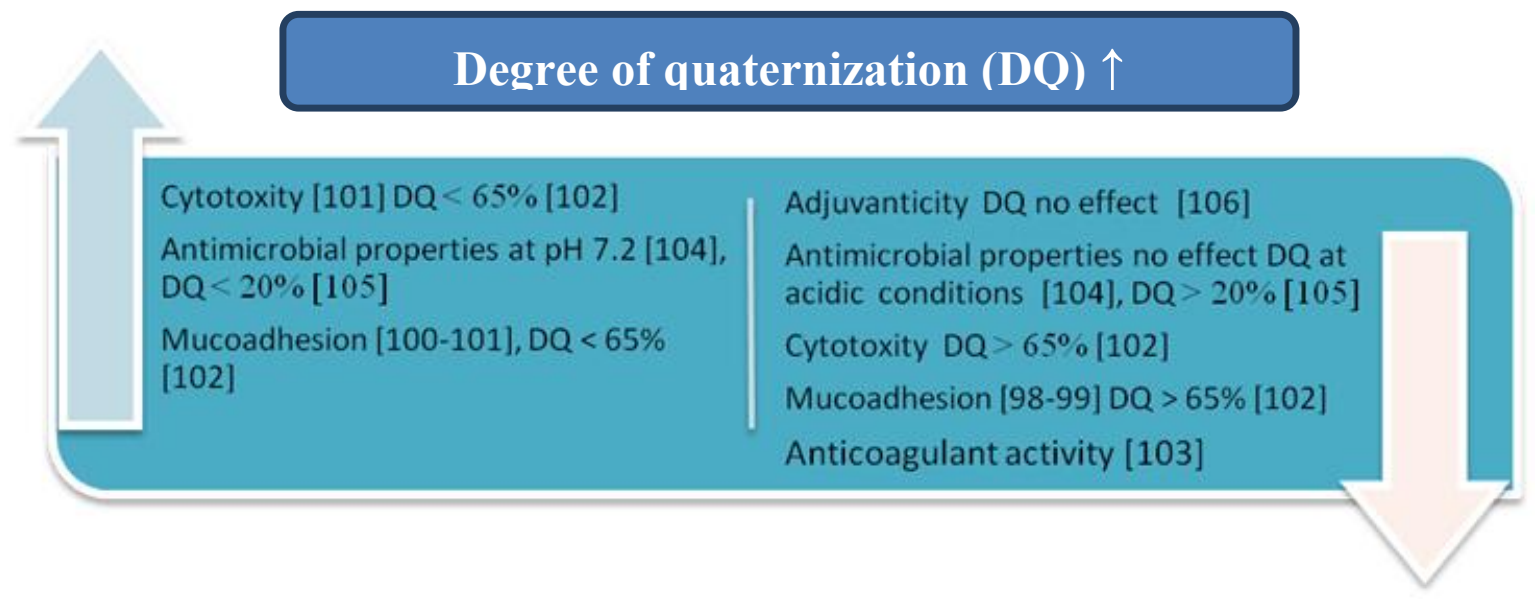

\section{Influence of the Degree of Substitution}

Chitin/chitosan contain three types of reactive functional groups: an amino/acetamido group at position C-2, and secondary and primary hydroxyl groups at positions C-3 and C-6 respectively. The degree of substitution of these groups may influence the biomedical properties of chitin/chitosan-based products (Figure 11).

Figure 11. Influence of degree of substitution on the physicochemical and biomedical properties of chitin/chitosan-based products.

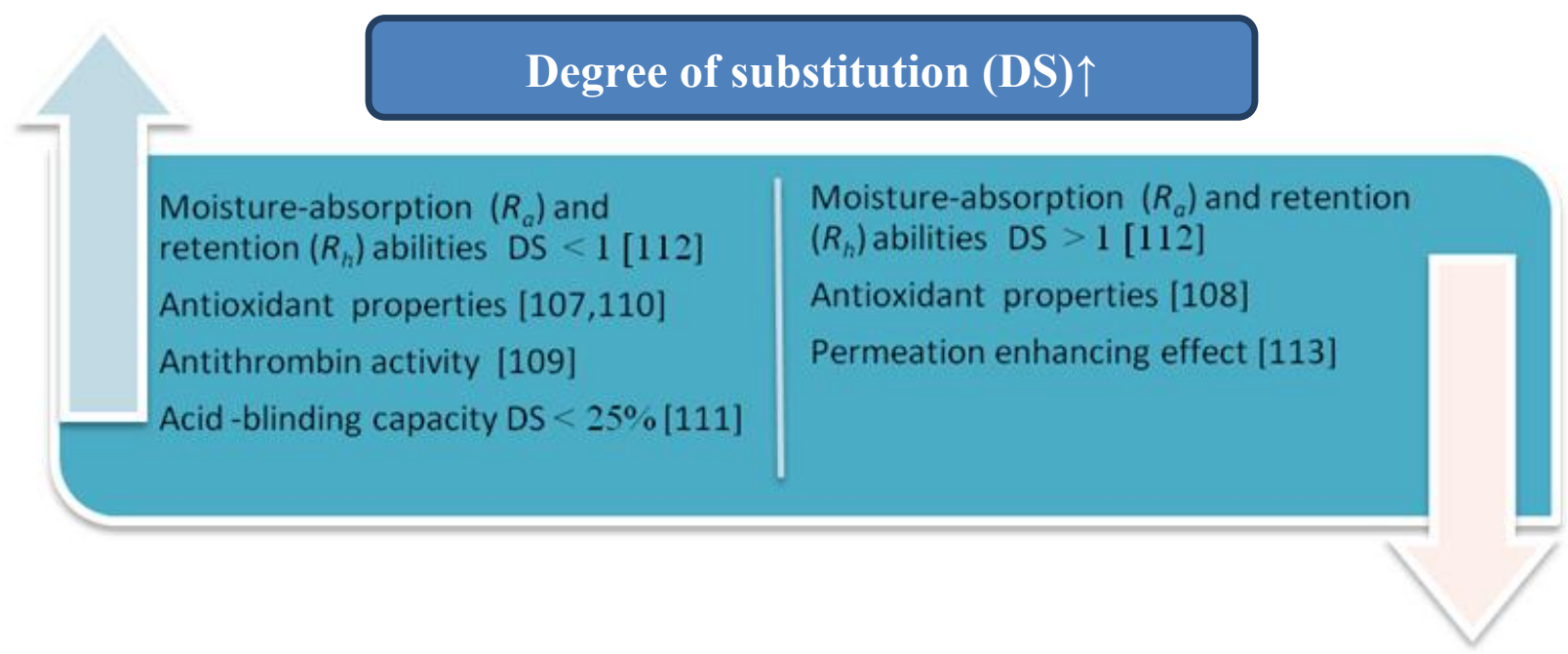

The influence of DS on antioxidant activity of branched-chain chitosan derivatives (the Schiff base-type chitosan-fructose derivative and $\mathrm{N}$-alkylated derivatives of chitosan) was investigated by Ying et al. [107]. The scavenging effect on DPPH increased with increasing DS, which was contrary to previously published data [108]. The scavenging effect of the $N$-alkylation chitosan derivative at concentrations lower than $0.5 \mathrm{mg} / \mathrm{mL}$ was negative, whereas for chitosan and Schiff base-type chitosan derivatives at any concentration was positive. Presumably, the increase in DS of the derivatives caused 
the decrease in $-\mathrm{NH}_{2}$ and the increase in $-\mathrm{OH}$ and $-\mathrm{N}=\mathrm{C}$ (Schiff base-type chitosan derivatives) or $-\mathrm{NH}-\mathrm{C}$ ( $N$-alkylation of chitosan derivatives). This indicates that the $-\mathrm{NH}_{2}$ and $-\mathrm{C}=\mathrm{N}$ had a better antioxidant ability than $-\mathrm{NH}-\mathrm{C}$.

Drozd et al. [109] compared the antithrombin activity of sulphated chitosan (CP) with different degrees of polymerization and sulphation in vivo and in vitro. An average molecular weight of $20-123 \mathrm{kDa}$ and sulphur contents of $8.8-16.9 \%$ were determined for these derivatives. The CPs with relatively low molecular weights $\left(\mathrm{M}_{\mathrm{W}} 61-82 \mathrm{kDa}\right.$, degrees of polymerization 188-252) and the high sulphation patterns (sulphur contents 15.6-16.9\%, sulphation degree 1.58-1.86) were characterized by a higher antithrombin activity (30-52 IU/mg). They recommend an in vivo system for evaluating the antithrombin activity of the CPs.

Xing et al. [110] described the effect of the preparation conditions of sulphated chitosans on their molecular weight and sulphur content. The sulphated chitosans they obtained contained $11.95-16.20 \%$ of sulphur, which corresponds to a degree of sulphation of 1.82-2.46 per glucosamine unit. The authors determined the antioxidant activity of high-molecular weight and high-sulphate-content chitosans (HCTS) and showed that HCTS could scavenge superoxide and hydroxyl radicals. Their $\mathrm{IC}_{50}$ values were 0.012 and $3.269 \mathrm{mg} / \mathrm{mL}$ respectively.

Yoo et al. [111] selectively modified the C-6 primary alcohol on chitosan by sequential TEMPO (2,2,6,6-tetramethyl-1-piperidine oxoammonium ion)-mediated oxidation and monitored the changes in water solubility at different levels of oxidation (from 25 to 100\%). Additionally, the biological functionality of 6-oxychitosan was examined by evaluating its bile acid-binding capacity. It was established that during the specific oxidation process, 25\%-oxidized 6-oxychitosan had the highest solubility, and the solubility decreased substantially from 0.72 to $0.15 \%$ as the degree of oxidation increased from 25 to $100 \%$. The binding capacity for $100 \%$-oxidized chitosan samples was only $4.5 \%$ better than the control sample. It was observed that 25\%-oxidized 6-oxychitosan displayed a much better binding capacity than any other sample groups.

The strongest cholic acid-retardation index (CRI, \%) of highly soluble 25\%-oxidized 6-oxychitosan was consistently observed until $24 \mathrm{~h}$ of dialysis, which means the CRI was closely related to the water solubility of 6-oxychitosan.

In another investigation, the relationships between the molecular structure and moisture-absorption and moisture-retention abilities of carboxymethyl chitosan with different degrees of $\mathrm{N}$-acetylation (DA 5-72\%) and carboxymethylation (DS 0.15-1.21) were studied by Chen et al. [112]. It was observed that the moisture-absorption $\left(R_{\mathrm{a}}\right)$ and -retention $\left(R_{\mathrm{h}}\right)$ abilities of carboxymethyl chitosans are closely related to the DA and DS values. Under conditions of high relative humidity, the maximum $R_{\mathrm{a}}$ and $R_{\mathrm{h}}$ were obtained at DA about $50 \%$. When the DA value deviated from $50 \%, R_{\mathrm{a}}$ and $R_{\mathrm{h}}$ decreased. Under dry conditions the $R_{\mathrm{h}}$ was the lowest when DA was $50 \%$, and $R_{\mathrm{a}}$ and $R_{\mathrm{h}}$ increased with increasing DS value. Carboxymethyl chitosans with DS from 0.6 to 1.0 showed $R_{\mathrm{a}}$ and $R_{\mathrm{h}}$ values equal to or better than those of hyaluronic acid. A further increase in DS above 1.0 reduced the increasing tendency of $R_{\mathrm{a}}$ and $R_{\mathrm{h}}$, and even some decreases in $R_{\mathrm{a}}$ and $R_{\mathrm{h}}$ were observed.

The effect of the $N$-betainate (DS 0.05-0.9) and $N$-piperazine derivatives (DS 0.15-0.9) of chitosan on the paracellular transport of mannitol and cell viability in the Caco-2 cell model were studied by Korjamo et al. [113]. The $N$-betainate derivative with the lowest degree of substitution (DS 0.05) was the most effective in the transport of mannitol at $1.0 \%(\mathrm{w} / \mathrm{v})$ concentration. The effect was essentially 
lost at DS $>0.15$. The activity of $N$-piperazines depended both on the DS and the number of quaternary nitrogens. Derivatives with lower DS were generally more active than those with higher DS values, but the fastest mannitol transport was slower than that achieved with the best $N$-betainate derivative. In general, the relationship between the degree of substitution and activity suggests that an intact chitosan backbone is essential for the bioactivity of chitosan derivatives. Chitosan $\mathrm{N}$-betainates should contain only the minimum number of substituents required to guarantee water solubility in order to reach the highest activity.

\section{Influence of the Preparation Techniques of chitin/Chitosan-Based Products Offered for Biomedical and Pharmaceutical Applications}

Chitin/chitosan-based products offered for biomedical and pharmaceutical applications are available in many different forms: nanoparticles, microspheres, hydrogels, films, fibers or tablets [30]. Considerable research efforts should be directed towards developing safe and efficient chitin/chitosan-based formulations. Agnihotri et al. [50] described the methods of preparing chitosan-based micro/nanoparticulate drug delivery systems. Chemically modified chitosan or its derivatives used in drug delivery systems are also reported. The choice of the method of preparation depends upon factors such as particle size requirement, the thermal and chemical stability of the active agent, reproducibility of the kinetic release profiles, stability of the final product and residual toxicity associated with the final product. All of these factors can influence the biomedical properties of chitin/chitosan-containing products (e.g., [114,115]).

For example, the drug release rates of theophylline, aspirin and griseofulvin from chitosan microspheres prepared by the emulsion cross-linking of a chitosan solution in paraffin oil as an external medium were influenced by cross-link density, particle size and initial drug loading [116].

Ko et al. [117] prepared chitosan microparticles with tripolyphosphate (TPP) by the ionic cross-linking method. Release behaviors of felodipine as a model drug were affected by various preparation processes. Chitosan microparticles prepared at a lower $\mathrm{pH}$ or a higher concentration of TPP solution resulted in slower felodipine release from microparticles. The release of this drug from TPP-chitosan microparticles decreased when the cross-linking time increased.

Katas and Oya Alpar [118] prepared chitosan nanoparticles using two methods of ionic cross-linking: simple complexation and ionic gelation using TPP. Both methods produced nanosized particles $(<500 \mathrm{~nm})$, depending on the type, molecular weight and concentration of chitosan. In the case of ionic gelation the TPP weight ratio and $\mathrm{pH}$ also affected the particle size. Chitosan-TPP nanoparticles with entrapped siRNA showed better properties as siRNA delivery vehicles than chitosan-siRNA complexes, possibly because of their high binding capacity and loading efficiency.

Yoskan et al. [114] described the preparation and evaluation of antimicrobial properties against silver nanoparticle-loaded chitosan-starch based films. The silver nanoparticles were prepared by $\gamma$-ray irradiation reduction of silver nitrate in a chitosan solution. They determined the minimum inhibitory concentration (MIC) of silver nanoparticles dispersed in chitosan solution. The films containing silver nanoparticles from 0.07 to $0.29 \%(\mathrm{w} / \mathrm{w})$ exhibited antimicrobial activity against Escherichia coli and two Gram-positive bacteria, Staphylococcus aureus and Bacillus cereus (the MIC value for all test bacteria was $5.64 \mu \mathrm{g} / \mathrm{mL}$ ). The author compared these results with other methods of silver nanoparticle 
preparation. Silver nanoparticles prepared by the application of Phytophthora infestans showed lower MICs: 0.313 and $0.625 \mu \mathrm{g} / \mathrm{mL}$ against $E$. coli and $S$. aureus respectively [119], whereas the MICs of Ag nanoparticles synthesized by an electrochemical method were 5 and $2 \mu \mathrm{g} / \mathrm{mL}$ against $E$. coli and S. aureus respectively [120]. In contrast, nanoparticles prepared by a process involving photoassisted reduction showed higher MIC values: 6.25 and $12.5 \mu \mathrm{g} / \mathrm{mL}$ against E. coli and $S$. aureus respectively [121]. The authors suggested that the difference in MIC values could be related to the variation in nanoparticle size and shape. Silver/chitosan nanocomposites were characterized by Cao et al. [122] in terms of their particle sizes and morphology. The antibacterial activities of these nanocomposites against $S$. aureus and $E$. coli were investigated. When the concentration of the silver ions increased, the inhibition ability of the silver/chitosan nanocomposites against both $E$. coli and S. aureus decreased, and the MIC (defined as the lowest silver/chitosan nanocomposite concentration resulting in a lack of visible microorganism growth) of the composites increased. These authors thought that when the concentration of the silver ions increased, the size of the silver nanoparticles obtained would increase as well. The larger particles have a smaller surface area and a smaller infiltration rate, which could lead to an inferior antibacterial activity. The shapes of the silver nanoparticles ions also influence antibacterial activity. When the atomic density of the polyhedron surface was higher, the antibacterial effects were more obvious [123].

Foster and Butt [115] confirmed the statement that the morphology of the final biomaterial can strongly influence the antimicrobial activity of chitosan biomaterials. They showed that while native chitosan solutions demonstrated strong bactericidal activity against $S$. aureus, S. epidermidis and E. coli (the complete inhibition $98 \pm 2 \%$ ), this beneficial property was lost in thin films cast from the same solutions. Chitosan films $(20 \mu \mathrm{m})$ showed no inhibitory effects against these bacteria. At pH 5 , chitosan solutions exhibited higher bactericidal effects of this biopolymer than at $\mathrm{pH} 7$.

In another study, Berger et al. [49] presented the physical properties of chitosan hydrogels formed by aggregation or complexation, which can be used in biomedical applications. It was noted that the preparation of grafted chitosan hydrogels was more complex and did not always improve biocompatibility compared to covalently cross-linked hydrogels. On the other hand, grafted chitosan hydrogels enhanced certain intrinsic properties of chitosan such as bacteriostasis tic and wound-healing.

The morphology and mechanical properties of chitosan fibers obtained by ageing gel-spinning were reported by Notin et al. [52]. They reported that ageing in the ambient atmosphere played an important role in the crystalline microstructure in relation to the kinetics of ammonium acetate hydrolysis, the formation of a weak fraction of the anhydrous allomorph of chitosan, and the increase in the crystallinity index, whereas Young's modulus (which quantifies the elasticity of the polymer) was higher and the tenacity slightly lowered. In addition, gel-jet-stretched or dry-jet-stretched fibers could be stored for at least 3 months in the ambient atmosphere without any significant degradation.

The antimicrobial activity of cotton fabrics treated with different cross-linking agents (butanetetracarboxylic acid (BTCA) and Arcofix NEC (low formaldehyde content)) and chitosan was tested by El-tahlawy et al. [124]. Both the type and concentration of the finishing agent in the presence of chitosan as well as the treatment conditions significantly affected the performance properties and antimicrobial activity of the treated cotton fabrics. The antimicrobial activity of cotton fabrics treated with BTCA was higher than that of the fabrics treated with Arcofix NEC. The maximum antimicrobial activity was obtained when the cotton fabrics were treated with $0.5-0.75 \%$ chitosan of molecular 
weight $1.5-5 \mathrm{kDa}$, and cured at $160{ }^{\circ} \mathrm{C}$ for $2-3$ min. Partial replacement of Arcofix NEC with BTCA enhanced the antimicrobial activity of the treated fabrics in comparison with that of Arcofix NEC alone.

González-Rodríguez et al. applied experimental statistics to study the formulation variables influencing the coating process of lidocaine hydrochloride (LID) liposomes by chitosan [125]. These variables were the concentration of the chitosan coating solution, the dripping rate of this solution on the liposome colloidal dispersion, the stirring rate, the time elapsing since the production of liposomes for the liposome coating and finally the amount of drug entrapped in the liposomes. The results indicated that the amount of LID was the predominant factor increasing the drug entrapment capacity (EE). The CE (\%) response was affected mainly by the concentration of the chitosan solution and the stirring rate, although all the interactions between the main factors are statistically significant.

Germershaus et al. [126] studied the relationships between chitosan, trimethyl chitosan and polyethyleneglycol-graft-trimethyl chitosan/DNA complex structures, their physicochemical properties (hydrodynamic diameter, condensation efficiency and DNA release), the cytotoxicity of these polymers, and the uptake- and transfection efficiency of polyplexes in vitro. The formation of aggregates of about $1,000 \mathrm{~nm}$ and with reduced DNA condensation efficiency were observed for all chitosan polyplexes. These authors established that quaternization of chitosan strongly reduced the aggregation tendency and the $\mathrm{pH}$ dependence of DNA complexation. Apart from a reduction in cytotoxicity, PEGylation improved the colloidal stability of polyplexes and significantly increased cellular uptake compared to unmodified trimethyl chitosan.

Jayakumar et al. [127] described the preparation, properties and biomedical applications of chitin and chitosan-based nanofibers. The influence of many factors (e.g., the process production, the chitosan concentration, viscosity or $\mathrm{PEO} /$ chitosan ratio) on the physicochemical characteristics and biomedical properties of the nanofibers obtained was also presented.

\section{Conclusions}

Chitin and chitosan are natural aminopolysaccharides with unique structures, multidimensional properties and highly sophisticated functions that are widely used in biomedical applications. Their microstructure and biomedical activity are strongly dependent on the source of chitin and the conditions of chitosan preparation. Knowledge of the structural differences among chitin/chitosan products is very important in determining the properties of these biopolymers and is essential for the structure-activity-analysis of biological systems. For medical applications, various forms of chitosan-based products are available, like finely-divided powders, films, membranes, nanoparticles or hydrogels. The potential implementation of chitosan in medicine can only be explored if its utilized form is properly developed and prepared. It is very important for biotech companies, which have to control different parameters influencing the characteristics of chitin/chitosan materials offered for biomedical applications, and will help to accelerate their future applications. So far, only the influence of the most important factors, such as the weight-averaged molecular weight $\left(\mathrm{M}_{\mathrm{W}}\right)$ and degree of $\mathrm{N}$-acetylation (DA) on the biomedical activity of chitin/chitosan products, have been investigated in detail and summarized in some papers. On the basis of literature data it has been possible to present in this review important information about the influence of other parameters such as the source of chitin 
and chitosan, $\mathrm{pH}$, the ionic strength, the concentration, the degree of quaternization, the degree of substitution, and the condition of preparation of chitin/chitosan-based products on their biomedical activity. Influence of selected key factors mentioned in the text on the physicochemical and biological properties of chitin/chitosan samples is summarized in Table 1.

Table 1. Influence of selected key factors mentioned in the text on the physicochemical and biological properties of chitin/chitosan samples (DS - degree of substitution, DQ - degree of quaternization, IS - ionic strength, $\mathrm{C}$ - concentration, $\mathrm{pH}$ ).

\begin{tabular}{|l|l|}
\hline \multicolumn{2}{|l|}{ Physicochemical properties $[$ References] } \\
\hline Solubility & $\mathrm{DQ} \uparrow[32-35]$ \\
\hline Syneresis & $\mathrm{pH}<4 \uparrow \mathrm{pH}>4 \downarrow[77]$; IS $\uparrow[77,84]$ \\
\hline Viscosity & $\mathrm{DQ} \uparrow[98]$ \\
\hline Cytotoxity & $\mathrm{DQ} \uparrow[101,102]$; C no effect for chitosan molecules [92]; $\uparrow$ for nanoparticles [92] \\
\hline $\begin{array}{l}\text { Moisture-absorption }\left(\boldsymbol{R}_{\boldsymbol{a}} \text { ) }\right. \\
\text { and -retention }\left(\boldsymbol{R}_{\boldsymbol{h}} \text { ) abilities }\right.\end{array}$ & $\mathrm{DS}<1 \uparrow, \mathrm{DS}>1 \downarrow[112]$ \\
\hline Zeta potential & $\mathrm{C} \uparrow[51]$ \\
\hline Intrinsic viscosity & $\mathrm{IS} \downarrow[83]$ \\
\hline Particle size & $\mathrm{C} \uparrow[51]$ \\
\hline Aggregation & $\mathrm{C} \uparrow[67,96]$ \\
\hline Drug loading & $\mathrm{pH} \uparrow[79]$ \\
\hline Entrapment efficiency & $\mathrm{pH} \uparrow[81]$ \\
\hline Biological properties & \\
\hline Antimicrobial & $\mathrm{DQ} \uparrow$ at $\mathrm{pH} 7.2$, no effect at acidic conditions [104], DQ up 20\% $\uparrow$ when $\downarrow[105] ;$ \\
\hline Antioxidant & $\mathrm{C} \uparrow[85-88,94,95] ; \mathrm{pH} \downarrow[68-74]$ \\
\hline Mucoadhesian & $\mathrm{DS} \uparrow[107,110] \downarrow \downarrow[108]$ \\
\hline Permeation enhancing effect & $\mathrm{DQ} \downarrow[98], \uparrow[100,101], \uparrow$ up to DQ $65 \%$ when $\downarrow[102]$ \\
\hline Antitumor & $\mathrm{DS} \downarrow[113] ; \mathrm{pH} \downarrow[80]$ \\
\hline Anticoagulant & $\mathrm{pH}<4$ or pH $>10 \uparrow[76]$ \\
\hline Adjuvanticity & $\mathrm{DQ} \downarrow[103]$ \\
\hline Antithrombin & $\mathrm{DQ}$ no effect [106] \\
\hline Acid-blinding capacity & $\mathrm{DS} \uparrow[109]$ \\
\hline Immune enhancing effect & $\mathrm{DS} \uparrow$ up to $25 \%[111]$ \\
\hline Calcium/cobalt blinding capacity & $\mathrm{pH}<4$ or $\mathrm{pH}>10 \uparrow[76]$ \\
\hline Transfection efficiency & $\mathrm{pH}[82]$ \\
\hline Gene knockdown efficiency & $\mathrm{C} \downarrow[51,89,90]$ \\
\hline$\uparrow$ directly proportion to property; $\downarrow$ inversely proportional to property \\
\hline
\end{tabular}

It should be also pointed that:

- when a chitosan solution is used in the investigations, factors such as concentration, $\mathrm{pH}$, ionic strength, the nature of salt counterion, and the addition of non-aqueous solvent should be taken into account, 
- chemical methods of modification can generate completely new chitin/chitosan-based biofunctional materials. For the obtained materials such parameters as the degree of quaternization and/or the degree of substitution should be determined and their influence on the investigated biological properties tested,

- the biological properties of chitin/chitosan materials used directly in biomedical applications (e.g., antimicrobial effects) could be different that observed for materials obtained after preparation of nanoparticles, microspheres, hydrogels, films, fibers or tablets,

- considerable research efforts should be directed towards developing safe and efficient chitin/chitosan-based formulations. As an example, such factors as particle size requirement, the thermal and chemical stability of the active agent, reproducibility of the kinetic release profiles, stability of the final product and residual toxicity associated with the final product depends upon the methods of preparing chitosan-based micro/nanoparticulate drug delivery systems,

- the influence of physicochemical properties apart from $\mathrm{M}_{\mathrm{W}}$ and $\mathrm{DA}$ on chitosan-based formulation affecting the delivery of DNA and siRNA [51] and on antimicrobial properties of chitin/chitosan materials [68-74,85-88,94,95,104,105] is the best known. For other biological properties our knowledge is still not sufficient,

- $\quad$ chitin/chitosan properties are interrelated and many times they could influence the bioactivity in a conflicting manner, e.g., would healing properties and permeation enhancement properties are inevitably linked to other such as mucoadhesion and cytotoxicity. For these reasons, these types of investigations should be continued.

\section{Acknowledgements}

The authors express their gratitude for the financial support provided by the Polish Ministry of Research and Higher Education under grant DS/8200-4-0085-1 and the German Academic Exchange Service (DAAD).

\section{References}

1. Roberts, G.A.F. Chitin Chemistry, 1st ed.; MacMillan: London, UK, 1992.

2. Muzzarelli, R.A.A. Natural Chelating Polymers; Pergamon Press: New York, NY, USA, 1973; p. 83.

3. Aiba, S. Studies on chitosan: 4. Lysozymic hydrolysis of partially $N$-acetylated chitosans. Int. J. Macromol. 1992, 14, 225-228.

4. Ravi Kumar, M.N.V. A review of chitin and chitosan applications. React. Funct. Polym. 2000, 46, 1-27.

5. Austin, P.R. Chitin solutions and purification of chitin. Methods Enzymol. 1988, 161, 403-407.

6. Pillai, C.K.S.; Paul W.; Sharma, C.P. Chitin and chitosan polymers: Chemistry, solubility and fiber formation. Prog. Polym. Sci. 2009, 34, 641-678.

7. Kurita, K. Controlled functionalization of the polysaccharide chitin. Prog. Polym. Sci. 2001, 26, 1921-1971.

8. Muzzarelli, R.A.A.; Jeuniaux, C.; Gooday, G.W. Chitin in Nature and Technology; Plenum Publishing Corporation: New York, NY, USA, 1986. 
9. Percot, A.; Viton, C.; Domard, A. Optimization of chitin extraction from shrimp shells. Biomacromolecules 2003, 4, 12-18.

10. Roberts, G. Chitin Chemistry, 2nd ed.; MacMillan: London, UK, 1998.

11. Chaussard, G.; Domard, A. New aspects of the extraction of chitin from squid pens. Biomacromolecules 2004, 5, 559-564.

12. Al Sagheer, F.A.; Al-Sughayer, M.A.; Muslim, S.; Elsabee, M.Z. Extraction and characterization of chitin and chitosan from marine sources in Arabian Gulf. Carbohydr. Polym. 2009, 77, 410-419.

13. Das, S.; Ganesh, E.A. Extraction of chitin from trash crabs (Podophthalmus vigil) by an eccentric method. Curr. Res. J. Biol. Sci. 2010, 2, 72-75.

14. Manni, L.; Ghorbel-Bellaaj, O.; Jellouli, K.; Younes, I.; Nasri, M. Extraction and characterization of chitin, chitosan, and protein hydrolysates prepared from shrimp waste by treatment with crude protease from bacillus cereus SV1. Appl. Biochem. Biotechnol. 2010, 162, 345-357.

15. Synowiecki, J.; Al-Khateeb, N.A. Production, properties, and some new applications of chitin and its derivatives. Crit. Rev. Food Sci. Nutr. 2003, 43, 145-171.

16. Tolaimate, A.; Desbrieres, J.; Rhazi, M.; Alagui, A. Contribution to the preparation of chitins and chitosans with controlled physico-chemical properties. Polymer 2003, 44, 7939-7952.

17. Aranaz, I.; Mengíbar, M.; Harris, R.; Paños, I.; Miralles, B.; Acosta, N.; Galed, G.; Heras, Á. Functional characterization of chitin and chitosan. Curr. Chem. Biol. 2009, 3, 203-230.

18. Weinhold, M.X.; Sauvageau, J.C.M.; Keddig, N.; Matzke, M.; Tartsch, B.; Grunwald, I.; Kübel, C.; Jastorff, B.; Thöming, J. Strategy to improve the characterization of chitosan for sustainable biomedical applications: SAR guided multi-dimensional analysis. Green Chem. 2009, 11, 498-509.

19. Rinaudo, M. Chitin and chitosan: Properties and application. Prog. Polym. Sci. 2006, 31, 603-632.

20. Domard, A. A perspective on 30 years research on chitin and chitosan. Carbohydr. Polym. 2010, doi: 10.1016/j.carbpol.2010.04.083.

21. Dash, M.; Chiellini, F.; Ottenbrite, R.M.; Chiellini E. Chitosan-A versatile semi-synthetic polymer in biomedical applications. Prog. Polym. Sci. 2011, 36, 981-1014.

22. Amidi, M.; Mastrobattista, E.; Jiskoot, W., Hennink, W.E. Chitosan-based delivery systems for protein therapeutics and antigens. Adv. Drug Deliv. Rev. 2010, 62, 59-82.

23. Agrawal, P.; Strijkers, G.J.; Nicolay, K. Chitosan-based delivery systems for protein therapeutics and antigens. Adv. Drug Deliv. Rev. 2010, 62, 59-82.

24. Khoushab, F.; Yamabhai, M. Chitin research revisited. Mar. Drugs 2010, 8, 1988-2012.

25. Yadav, A.V.; Bhise, B.B. Chitosan a potential biomaterial effective against typhoid. Curr. Sci. 2004, 187, 1176-1178.

26. Krajewska, B. Application of chitin- and chitosan-based materials for enzyme immobilizations: A review. Enzyme Microb. Technol. 2004, 35, 126-139.

27. Murugan, R.; Ramakrishna, S. Bioresorbable composite bone paste using polysaccharide based nanohydroxyapatite. Biomaterials 2004, 25, 3829-3835. 
28. Muzzarelli, R.A.A.; Muzzarelli, C. Chitosan chemistry: Relevance to the biomedical sciences. Adv. Polym. Sci. 2005, 186, 151-209.

29. Di Martino, A.; Sittinger, M.; Risbud, M.V. Chitosan: A versatile biopolymer for orthopaedic tissue-engineering. Biomaterials 2005, 26, 5983-5990.

30. Ravi Kumar, M.N.V.; Muzzarelli, R.A.A.; Muzzarelli, C.; Sashiwa, H.A.; Domb, J. Chitosan chemistry and pharmaceutical perspectives. Chem. Rev. 2004, 104, 6017-6084.

31. Xia, W.; Liu, P.; Zhang, J.; Chen, J. Biological activities of chitosan and chitooligosaccharides. Food Hydrocoll. 2010, doi: 10.1016/j.foodhyd.2010.03.003.

32. Jayakumar, R.; Prabaharan, M.; Nair, S.V.; Tokura, S.; Tamura, H.; Selvamurugan, N. Novel carboxymethyl derivatives of chitin and chitosan materials and their biomedical applications. Prog. Mater. Sci. 2010, 55, 675-709.

33. Zhong, Z.; Chen, R.; Xing, R.; Chen, X.; Liu, S.; Guo, Z.; Ji, X.; Wang, L.; Li, P. Synthesis and antifungal properties of sulfanilamide derivatives of chitosan. Carbohydr. Res. 2007, 342, 2390-2395.

34. Xie, Y.; Liu, X.; Chen, Q. Synthesis and characterization of water-soluble chitosan derivate and its antibacterial activity. Carbohydr. Polym. 2007, 69, 142-147.

35. Jeong, Y.-I.; Kim, D.-G.; Jang, M.-K.; Nah, J.-W. Preparation and spectroscopic characterization of methoxy poly(ethylene glycol)-grafted water-soluble chitosan. Carbohydr. Res. 2008, 343, 282-289.

36. Aranaz, I.; Harris, R.; Heras, A. Chitosan amphiphilic derivatives. Chemistry and applications. Curr. Org. Chem. 2010, 14, 308-330.

37. Alves, N.M.; Mano, J.F. Chitosan derivatives obtained by chemical modifications for biomedical and environmental applications. Int. J. Biol. Macromol. 2008, 43, 401-414.

38. Struszczyk, M.H.; Struszczyk, K.J. Medical Application of Chitin and Its Derivatives; Polish Chitin Society, Monograph XII: Łódź, Poland, 2007; pp. 139-147.

39. ASTM. F2103-01 Standard Guide for Characterization and Testing of Chitosan Salts as Starting Materials Intended for Use in Biomedical and Tissue-Engineered Medical Product Applications; ASTM: West Conshohocken, PA, USA, 2001.

40. ASTM. F2260-03 Standard Test Method for Determining Degree of Deacetylation in Chitosan Salts by Proton Nuclear Magnetic Resonance (1H NMR) Spectroscopy; ASTM: West Conshohocken, PA, USA, 2003.

41. ASTM. WK965 New Test Method for Determining the Molar Mass of Chitosan and Chitosan Salts by Size Exclusion Chromatography with Multi-Angle Light Scattering Detection (SEC-MALS); ASTM: West Conshohocken, PA, USA, 2003.

42. Kean, T.; Thanou, M. Biodegradation, biodistribution and toxicity of chitosan. Adv. Drug Deliv. Rev. 2010, 62, 3-11.

43. No, H.K.; Park, N.Y.; Lee, S.H.; Meyers, S.P. Antibacterial activity of chitosans and chitosan oligomers with different molecular weights. Int. J. Food Microbiol. 2002, 74, 65-72.

44. Kumirska, J.; Weinhold, M.X.; Czerwicka, M.; Kaczyński, Z.; Bychowska, A.; Brzozowski, K.; Thöming, J.; Stepnowski, P. Influence of the chemical structure and physicochemical properties of chitin- and chitosan-based materials on their biomedical activity. In Biomedical Engineering, Trends in Materials Science; Laskovski, A.N., Ed.; InTech: Rijeka, Croatia, 2011; pp. 25-64. 
45. Tsao, C.T.; Chang, C.H.; Lin, Y.Y.; Wu, M.F.; Wang, J.-L.; Han, J.L.; Hsieh, K.H. Antibacterial activity and biocompatibility of a chitosan- $\gamma$-poly(glutamic acid) polyelectrolyte complex hydrogel. Carbohydr. Res. 2010, 345, 1774-1780.

46. Kong, M.; Chen, X.G.; Xing, K.; Park, H.J. Antimicrobial properties of chitosan and mode of action: A state of the art review. Int. J. Food Microbiol. 2010, 144, 51-63.

47. Boonsongrit, Y.; Mitrevej, A.; Mueller, B.W. Chitosan drug binding by ionic interaction. Eur. J. Pharm. Biopharm. 2006, 62, 267-274.

48. Park, J.H.; Saravanakumar, G.; Kim, K.; Kwon, I.C. Targeted delivery of low molecular drugs using chitosan and its derivatives. Adv. Drug Deliv. Rev. 2010, 62, 28-41.

49. Berger, J.; Reist, M.; Mayer, J.M.; Felt, O.; Gurny, R. Structure and interactions in chitosan hydrogels formed by complexation or aggregation for biomedical applications. Eur. J. Pharm. Biopharm. 2004, 57, 35-52.

50. Agnihotri, S.A.; Mallikarjuna, N.N.; Aminabhavi, T.M. Recent advances on chitosan-based micro- and nanoparticles in drug delivery. J. Control. Release 2004, 100, 5-28.

51. Mao, S.; Sun, W.; Kissel, T. Chitosan-based formulations for delivery of DNA and siRNA. Adv. Drug Deliv. Rev. 2010, 62, 12-27.

52. Notin, L.; Viton, C.; David, L.; Alcouffe, P.; Rochas, C.; Domard, A. Morphology and mechanical properties of chitosan fibers obtained by gel-spinning: Influence of the dry-jet-stretching step and ageing. Acta Biomater. 2006, 2, 387-402.

53. Ranjbar-Mohammadi, M.; Arami, M.; Bahrami, H.; Mazaheri, F.; Mahmoodi, N.M. Grafting of chitosan as a biopolymer onto wool fabric using anhydride bridge and its antibacterial property. Colloids Surf. B Biointerfaces 2010, 76, 397-403.

54. Rinki, K.; Dutta, P.K. Physicochemical and biological activity study of genipin-crosslinked chitosan scaffolds prepared by using supercritical carbon dioxide for tissue engineering applications. Int. J. Biol. Macromol. 2010, 46, 261-266.

55. Beckham, G.T.; Crowley, M.F. Examination of the $\alpha$-chitin structure and decrystallization thermodynamics at the nanoscale. J. Phys. Chem. B 2011, 115, 4516-4522.

56. Campana-Filho, S.P.; de Britto, D.; Curti, E.; Abreu, F.R.; Cardoso, M.B.; Battisti, M.V. Sim, P.C.; Goy, R.C.; Signini R.L.; Lavall, R. Extraction, structures and properties of $\alpha$ - and $\beta$-chitin. Quim. Nova 2007, 30, 644-650.

57. Kurita, K.; Ishii, S.; Tomita, K.; Nishimura, S.I.; Shimoda, K. Reactivity characteristics of squid $\beta$-chitin ascompared with those of shrimp chitin: High potentials of squid chitin as a starting material for facile chemical modifications. J. Polym. Sci. Part A Polym. Chem. 1994, 32, 1027-1032.

58. Sannan, T.; Kurita, K.; Iwakura, Y. Studies on chitin 2. Effect of deacetylation on solubility. Makromol. Chem. 1976, 177, 3589-3600.

59. Noishiki, Y.; Takami, H.; Nishiyama, Y.; Wada, M.; Okada, S.; Kuga, S. Alkali-induced conversion of $\beta$-chitin to $\alpha$-chitin. Biomacromolecules 2003, 4, 896-899.

60. Youn, D.K.; No, H.K.; Prinyawiwatkul, W. Physicochemical and functional properties of chitosans prepared from shells of crabs harvested in three different years. Carbohydr. Polym. 2009, 78, 41-45. 
61. Wu, T.; Zivanovic, S.; Draughon, F.A.; Conway, W.S.; Sams, C.E. Physicochemical properties and bioactivity of fungal chitin and chitosan. J. Agric. Food Chem. 2005, 53, 3888-3894.

62. New, N.; Stevens, W.F.; Montet, D.; Tokura, S.; Tamura, H. Decomposition of myceliar matrix and extraction of chitosan from Gongronella butleri USDB 0201 and Absidia coeruleareak ATCC 14076. Int. J. Biol. Macromol. 2008, 43, 2-7.

63. Kamil, J.Y.V.A.; Jeon, Y.-J.; Shahidi, F. Antioxidative activity of chitosans of different viscosity in cooked comminuted flesh of herring (Clupea harengus). Food Chem. 2002, 79, 69-77.

64. Baskar, D.; Sampath Kumar, T.S. Effect of deacetylation time on the preparation, properties and swelling behavior of chitosan films. Carbohydr. Polym. 2009, 78, 767-772.

65. Kim, I.-Y; Seo, S.-J.; Moon, H.-S.; Yoo, M.-K.; Park, I.-Y.; Kim, B.-C.; Cho, C.-S. Chitosan and its derivatives for tissue engineering applications. Biotechnol. Adv. 2008, 26, 1-21.

66. Madihally, S.V.; Matthew, H.W.T. Porous chitosan scaffolds for tissue engineering. Biomaterials 1999, 20, 1133-1142.

67. Elsabee, M.Z.; Morsi, R.E.; Al-Sabagh, A.M. Surface active properties of chitosan and its derivatives. Colloids Surf. B Biointerfaces 2009, 74, 1-16.

68. Singh, J.P.; Dutta, K. Antibacterial and physiochemical behavior of prepared chitosan/pyridine3,5-di-carboxylic acid complex for biomedical applications. J. Macromol. Sci. Pure Appl. Chem. 2011, 48, 246-253.

69. Aiedeh, K.; Taha, M.O. Synthesis of iron-crosslinked chitosan succinate and ironcrosslinked hydroxamated chitosan succinate and their in vitro evaluation as potential matrix materials for oral theophylline sustained-release beads. Eur. J. Pharm. Sci. 2001, 13, 159-168.

70. Sudarshan, N.R.; Hoover, D.G.; Knorr, D. Antibacterial action of chitosan. Food Biotechnol. 1992, 6, 257-272.

71. Papineau, A.M.; Hoover, D.G.; Knorr, D.; Farkas, D.F. Antimicrobial effect of watersoluble chitosans with high hydrostatic pressure. Food Biotechnol. 1991, 5, 45-57.

72. Helander, I.M.; Nurmiaho-Lassila, E.L.; Ahvenainen, R.; Rhoades, J.; Roller, S. Chitosan disrupts the barrier properties of the outer membrane of Gram-negative bacteria. Int. J. Food Microbiol. 2001, 71, 235-244.

73. Kong, M.; Chen, X.G.; Liu, C.S.; Yu, L.J.; Ji, Q.X.; Xue, Y.P.; Cha, D.S.; Park, H.J. Preparation and antibacterial activity of chitosan microspheres in a solid dispersing system. Front. Mater. Sci. China 2008, 2, 214-220

74. Yang, T.C.; Chou, C.C.; Li, C.F. Antibacterial activity of $N$-alkylated disaccharide chitosan derivatives. Int. J. Food Microbiol. 2005, 97, 237-245.

75. Zeng, L.; Qin, C.; Chi, W.; Wang, L.; Ku, Z.; Li, W. Browning of chitooligomers and their optimum preservation. Carbohydr. Polym. 2007, 67, 551-558.

76. Kim, S.K.; Rajapakse, N. Enzymatic production and biological activities of chitosan oligosaccharides (COS): A review. Carbohydr. Polym. 2005, 62, 357-368.

77. Vachoud, L.; Zydowicz, N.; Domard, A. Physicochemical behaviour of chitin gels. Carbohydr. Res. 2000, 326, 295-304.

78. Boonsongrit, Y.; Mitrevej, A.; Mueller, B.W. Chitosan drug binding by ionic interaction. Eur. J. Pharm. Biopharm. 2006, 62, 267-274. 
79. Sahoo, S.; Sasmal, A.; Nanda, R.; Phani, A.R.; Nabak, P.L. Synthesis of chitosan-polycaprolactone blend for control delivery of ofloxacin drug. Carbohydr. Polym. 2010, 79, 106-113.

80. Guliyeva, U.; Öner, F.; Özsoy, S.; Haziroğlu, R. Chitosan microparticles containing plasmid DNA as potential oral gene delivery system. Eur. J. Pharm. Biopharm. 2006, 62, 17-25.

81. Monier, M.; Wei, Y.; Sarhan, A.A. Evaluation of the potential of polymeric carriers based on photo-crosslinkable chitosan in the formulation of lipase from Candida rugosa immobilization. J. Mol. Catal. B Enzym. 2010, 63, 93-101.

82. Bernkop-Schnürch, A.; Krajicek, M.E. Mucoadhesive polymers as platforms for peroral peptide delivery and absorption: Synthesis and evaluation of different chitosan-EDTA conjugates. J. Control. Release 1998, 50, 215-223.

83. Rinaudo, M.; Milas M.; Le Dung, P. Characterization of chitosan. Influence of ionic strength and degree of acetylation on chain expansion. Int. J. Biol. Macromol. 1993, 15, 281-285.

84. Laplante, S.; Turgeon, S.L.; Paquin, P. Effect of $\mathrm{pH}$, ionic strength, and composition on emulsion stabilizing properties of chitosan in a model system containing whey protein isolate. Food Hydrocolloids 2005, 19, 721-729.

85. EI-Ghaouth, A.; Arul, J.; Asselin, A.; Benhamou, N. Antifungal activity of chitosan on post-harvest pathogens: Induction of morphological and cytological alterations in Rhizopus stolonifer. Mycol. Res. 1992, 96, 769-779.

86. Abou Sereih Neven, A.; Abd-El-Aal, S.K.H.; Sahab, A.F. The mutagenic activity of chitosan and its effect on the growth of Trichoderma harzianum and Fusarium oxysporum F. Sp. Sesami. J. Appl. Sci. Res. 2007, 3, 450-455.

87. Zhong, Z.; Li, P.; Xing, R.; Liu, S. Antimicrobial activity of hydroxylbenzenesulfonailides derivatives of chitosan, chitosan sulfates and carboxymethyl chitosan. Int. J. Biol. Macromol. 2009, 45, 163-168.

88. Xie, W.; Xu, P.; Wang, W.; Liu, Q. Preparation and antibacterial activity of a water-soluble chitosan derivative. Carbohydr. Polym. 2002, 50, 35-40.

89. Sajomsang, W.; Ruktanonchai, U.; Gonil, P Mayen, V.; Opanasopit, P. Methylated N-aryl chitosan derivative/DNA complex nanoparticles for gene delivery: Synthesis and structure-activity relationships. Carbohydr. Polym. 2009, 78, 743-752.

90. Liu, X.; Howard, K.A.; Dong, M.; Andersen, M.O.; Rahbek, U.L.; Johnsen, M.G.; Hansen, O.C.; Besenbacher, F.; Kjems, J. The influence of polymeric properties on chitosan/siRNA nanoparticle formulation and gene silencing. Biomaterials 2007, 28, $1280-1288$.

91. Zhu, A.; Chan-Park, M.B.; Dai, S.; Li, L. The aggregation behavior of $O$-carboxymethylchitosan in dilute aqueous solution. Colloids Surf. B Biointerfaces 2005, 43, 143-149.

92. Loh, J.W.; Yeoh, G.; Saunders, M.; Lim, L.-Y. Uptake and cytotoxicity of chitosan nanoparticles in human liver cells. Toxicol. Appl. Pharmacol. 2010, 249, 148-157.

93. Yuan, N.-Y.; Tsai, R.-Y.; Ho, M.-H.; Wang, D.-M.; Lai, J.-Y.; Hsieh, H.-J. Fabrication and characterization of chondroitin sulfate-modified chitosan membranes for biomedical applications. Desalination 2008, 234, 166-174. 
94. Cai, Z.-X.; Mo, X.-M.; Zhang, K.-H.; Fan, L.-P.; Yin, A.-L.; He, C.-L.; Wang, H.-S. Fabrication of chitosan/silk fibroin composite nanofibers for wound-dressing applications. Int. J. Mol. Sci. 2010, 11, 3529-3539.

95. Yang, L.; Hsiao, W.W.; Chen, P. Chitosan-cellulose composite membrane for affinity purification of biopolymers and immunoadsorption. J. Membr. Sci. 2002, 197, 185-197.

96. Pepić, I.; Filipović-Grčić, J.; Jalšenjak, I. Interactions in a nonionic surfactant and chitosan mixtures. Colloids Surf. A Physicochem. Eng. Asp. 2008, 327, 95-102.

97. Muzzarelli, R.A.A.; Tanfani, F. The $N$-permethylation of chitosan and the preparation of $N$-trimethyl chitosan iodide. Carbohydr. Polym. 1985, 5, 297-307.

98. Snyman, D.; Hamman, J.H.; Kotze, A.F. Evaluation of the mucoadhesive properties of N-trimethyl chitosan chloride. Drug Dev. Ind. Pharm. 2003, 29, 61-69.

99. Snyman, D.; Hamman, J.H.; Kotze, A.F.; Rollings, J.E.; Kotze, A.F. The relationship between the absolute molecular weight and the degree of quaternisation of $N$-methyl chitosan chloride. Carbohydr. Polym. 2002, 50, 145-150.

100. Sandri, G.; Rossi, S.; Bonferoni, M.C.; Ferrari, F.; Zambito, Y.; Di Colo, G.; Caramella, C. Buccal penetration enhancement properties of $N$-trimethyl chitosan: Influence of quaternization degree on absorption of a high molecular weight molecule. Int. J. Pharm. 2005, 297, 146-155.

101. Jintapattanakit, A.; Mao, S.; Kissel, T.; Junyaprasert, V.B. Physicochemical properties and biocompatibility of $\mathrm{N}$-trimethyl chitosan: Effect of quaternization and dimethylation. Eur. $J$. Pharm. Biopharm. 2008, 70, 563-571.

102. Sajomsang, W.; Ruktanonchai, U.R.; Gonil, P.; Nuchuchua, O. Mucoadhesive property and biocompatibility of methylated $\mathrm{N}$-aryl chitosan derivatives. Carbohydr. Polym. 2009, 78, 945-952.

103. Huang, R.; Du, Y.; Yang, J.; Fan, L. Influence of functional groups on the in vitro anticoagulant activity of chitosan sulfate. Carbohydr. Res. 2003, 338, 483-489.

104. Rúnarsson, O.V.; Holappa, J.; Nevalainen, M.; Hjálmarsdóttir, T.; Järvinen, T.; Loftsson, T.; Einarsson, J.M.; Jónsdóttir, S.; Valdimarsdóttir, M.; Másson, M. Antibacterial activity of methylated chitosan and chitooligomer derivatives: Synthesis and structure activity relationships. Eur. Polym. J. 2007, 43, 2660-2671.

105. Sajomsang, W.; Tantayanon S.; Tangpasuthadol, V.; Daly, W.H. Quaternization of $N$-aryl chitosan derivatives: Synthesis, characterization, and antibacterial activity. Carbohydr. Res. 2009, 344, 2502-2511.

106. Hagenaars, N.; Verheul, R.J.; Mooren, I.; de Jong, P.H.J.L.F.; Mastrobattista, E.; Glansbeek, H.L.; Heldens, J.G.M.; van den Bosch, H.; Hennink, W.E.; Jiskoot, W. Relationship between structure and adjuvanticity of $N, N, N$-trimethyl chitosan (TMC) structural variants in a nasal influenza vaccine. J. Control. Release 2009, 140, 126-133.

107. Ying, G.-Q.; Xiong, W.-Y.; Wang, H.; Sun, Y.; Liu, H.-Z. Preparation, water solubility and antioxidant activity of branched-chain chitosan derivatives. Carbohydr. Polym. 2011, 83, 1787-1796.

108. Lin, H.Y.; Chou, C.C. Antioxidative activities of water-soluble disaccharide chitosan derivatives. Food Res. Int. 2004, 34, 883-889. 
109. Drozd, N.N.; Sher, A.I.; Makariv, V.A.; Galbraikh, L.S.; Vikhoreva, G.A.; Garbachiova, I.N. Comparison of antithrombin activity of the polysulphate chitosan derivatives in vivo and in vitro system. Thrombosis Res. 2001, 102, 445-455.

110. Xing, R.; Liu, S.; Yu, H.; Guo, Z.; Li, Z.; Li, P. Preparation of high-molecular weight and high-sulfate content chitosans and their potential antioxidant activity in vitro. Carbohydr. Polym. 2005, 61, 148-154.

111. Yoo, S.-H.; Lee, J.-S.; Park, S.Y.; Kim, Y.-S.; Chang, P.-S.; Lee, H.G. Effects of selective oxidation of chitosan on physical and biological properties. Int. J. Biol. Macromol. 2005, 35, 27-31.

112. Chen, L.; Du, Y.; Zeng, X. Relationships between the molecular structure and moisture-absorption and moisture-retention abilities of carboxymethyl chitosan II. Effect of degree of deacetylation and carboxymethylation. Carbohydr. Res. 2003, 338, 333-340.

113. Korjamo, T.; Holappa, J.; Taimisto, S.; Savolainen, J.; Järvinen, T.; Mönkkönen, J. Effect of $\mathrm{N}$-betainate and $\mathrm{N}$-piperazine derivatives of chitosan on the paracellular transport of mannitol in Caco-2 cells. Eur. J. Pharm. Sci. 2008, 35, 226-234.

114. Yoksan, R.; Chirachanchai, S. Silver nanoparticle-loaded chitosan-starch based films: Fabrication and evaluation of tensile, barrier and antimicrobial properties. Mater. Sci. Eng. C Mater. Biol. Appl. 2010, 30, 891-897.

115. Foster, L.J.R.; Butt, J. Chitosan films are NOT antimicrobial. Biotechnol. Lett. 2011, 33, 417-421.

116. Thanoo, B.C.; Sunny, M.C.; Jayakrishnan, A. Cross-linked chitosan microspheres: Preparation and evaluation as a matrix for the controlled release of pharmaceuticals. J. Pharm. Pharmacol. 1992, 44, 283-286.

117. Ko, J.A.; Park, H.J.; Hwang, S.J.; Park, J.B.; Lee, J.S. Preparation and characterization of chitosan microparticles intended for controlled drug delivery. Int. J. Pharm. 2002, 249, $165-174$.

118. Katas, H.; Oya Alpar, H. Development and characterisation of chitosan nanoparticles for siRNA delivery. J. Control. Release 2006, 115, 216-225.

119. Thirumurugan, G.; Shaheedha, S.M.; Dhanaraju, M.D. In-vitro evaluation of anti-bacterial activity of silver nanoparticles synthesised by using phytophthora infestans. Int. J. ChemTech. Res. 2009, 1, 714-716.

120. Khaydarov, R.R.; Khaydarov, R.A.; Gapurova, O.; Estrin, Y.; Evgrafova, S.; Scheper, T.; Cho, S.Y. Antimicrobial Effects of Silver Nanoparticles Synthesized by an Electrochemical Method. In Nanostructured Materials for Advanced Technological Applications; Reithmaier, J.P., Petkov, P., Kulisch, W., Popov, C., Eds.; Springer: Dordrecht, The Netherlands, 2009; pp. 215-218.

121. Jain, J.; Arora, S.; Rajwade, J.M.; Omray, P.; Khandelwal, S.; Paknikar, K.M. Silver nanoparticles in therapeutics: Development of an antimicrobial gel formulation for topical use. Mol. Pharm. 2009, 6, 1388-1401.

122. Cao, X.L.; Cheng, C.; Ma, Y.L.; Zhao, C.S. Preparation of silver nanoparticles with antimicrobial activities and the researches of their biocompatibilities. J. Mater. Sci.: Mater. Med. 2010, 21, 2861-2868. 
123. Sharma, V.K.; Yngard, R.A.; Lin, Y. Silver nanoparticles: Green synthesis and their antimicrobial activities. Adv. Colloid Interface Sci. 2009, 145, 83-96.

124. El-Tahlawy, K.F.; El-Bendary, M.A.; Elhendawy, A.G.; Hudson, S.M. The antimicrobial activity of cotton fabrics treated with different crosslinking agents and chitosan. Carbohydr. Polym. 2005, 60, 421-430.

125. González-Rodríguez, M.L.; Barros, L.B.; Palma, J.; González-Rodríguez, P.L.; Rabasco, A.M. Application of statistical experimental design to study the formulation variables influencing the coating process of lidocaine liposomes. Int. J. Pharm. 2007, 337, 336-345.

126. Germershaus, O.; Mao, S.; Sitterberg, J.; Bakowsky, U.; Kissel, T. Gene delivery using chitosan, trimethyl chitosan or polyethylenglycol-graft-trimethyl chitosan block copolymers: Establishment of structure-activity relationships in vitro. J. Control. Release 2008, 125, 145-154.

127. Jayakumar, R.; Prabaharan, M.; Nair, S.V.; Tamura, H. Novel chitin and chitosan nanofibers in biomedical applications. Biotechnol. Adv. 2010, 28, 142-150.

(C) 2011 by the authors; licensee MDPI, Basel, Switzerland. This article is an open access article distributed under the terms and conditions of the Creative Commons Attribution license (http://creativecommons.org/licenses/by/3.0/). 